the whole atmosphere, which is continually tending to produce them at intervals of about $45^{\circ}$ of longitude.

Perhaps the most important conclusion reached by Sir George Simpson in the first report of this series, which appeared in 1919 , is that relating to the travel of pressure changes in the Ross Sea region, deduced from synchronous observations made at Framheim, Cape Evans and Cape Adare. He concluded that it is only quite exceptionally that the barometric maxima and minima at these places are caused by travelling cyclones and anticyclones, and that as a rule they are due to "long and deep pressure waves radiating out from the Antarctic continent and extending over the Southern Ocean to some unknown distance from the Continent, traces of which can still be seen in the pressure curves for Kerguelen". He obtained evidence to show that the centre from which the waves radiated was not at the Pole but in about lat. $80^{\circ} \mathrm{S}$., long. $120^{\circ} \mathrm{W}$. With these conclusions Dr. Kidson, it appears, is not in agreement, largely as a result of the construction of the daily weather charts reproduced in this seventh report. He subjects the data used by Simpson to a fresh analysis and remarks, when discussing the times of occurrence of pressure changes at Cape Evans, Adélie Land and Queen Mary Land, that it seems quite impossible to reconcile these with the idea that the pressure maxima are caused by pressure waves as described by Simpson.

It may seem at first sight rather surprising that after such thorough analysis of the meteorological observations of this Expedition, there should be disagreement on such a fundamental point; but many of Dr. Kidson's daily weather charts show a feature that may partly account for this state of affairs, and that is the extent to which the fronts are bent towards a west-east orientation as they reach high latitudes, with an accompanying diminution in the temperature contrasts between the cold and warm air. This tends to make identification of fronts difficult; moreover, when the front is bent almost to an east-west orientation, the intervals of time separating its eastward passage across stations in different longitudes can be greatly affected by small differences between the latitudes of such stations. It is, however, a matter that can scarcely fail to be settled. as the number of observing stations is increased.

\section{WORLD FORESTRY AND FOREST PRODUCTS}

A PRELIMINARY investigation of the greatest importance has been carried out by the Forestry Section of the Food and Agriculture Organisation in connexion with the examination of the world's resources in forests*, and a consideration of improved methods by which these resources should be utilized and improved. It is stated that this investigation could only be a preliminary one.

Almost one-third of the earth's surface, 4,000 million hectares, is classified as forest soil. These soils occupy twice as much area as all the land under cultivation, but their contribution to human welfare, while very great, could be increased many times if the 500 million hectares now denuded and useless could be restored, and if the 2,000 million hectares yet untouched could be opened and put under good

- Food and Agriculture Organisation Forestry and Forest Products. World Situation 1937-1946. Pp. 93. (Washington, D.C., 1946.) management. Only one-third of the world's forest area has so far been brought into use, and less than 300 million hectares are under systematic forest management. The other thousand million hectares which constitute the overwhelming bulk of all forests in use are cut with little or no regard to their con. tinued productivity. In other words, forest management is still fairly limited, since it extends at best to one-fourth of all forests in use, and to less than 10 per cent of the world's forest soils.

The preface of this report is written by Sir John Boyd Orr, director-general of the Food and Agricul. ture Organisation, and he commences by saying: "In dedicating itself to the goal of freedom from want, F.A.O. must devote a major effort to restoration of the world's forests, and to the effective use of their products". With the appointment of Marcel Leloup, formerly director-general of the Department des Eaux et Forêts in France, as director of forestry and forest products in the Organisation, the first step in making international forestry an accomplished fact was taken. As this brochure displays, already a certain amount of world forest statistics had been gathered together but, as Boyd Orr says : "The goal before the Branch lies far beyond initiating statistics and collecting information. Forestry in F.A.O. will take an active part in helping Member Governments deal with their forest problems and in advising them on their forest policies."

One of the studies already made is the result of war's impact on forests, particularly in Europe. Here the direct effects were found to be far less damaging than had been expected. Land and aerial warfare inflicted serious local damage only in the areas of actual fighting. With the exception of the forests of Greece and Poland, which were badly devastated, European forests emerged from the War practically intact. On the other hand, over-cutting in the accessible forests throughout the world, enhanced during the War, has been very serious, and post-war requirements, especially perhaps building requirements in Western Europe, including Britain, are placing an added burden on the forests in which already excess fellings have been made.

Some of the causes of the present scarcity, such as insufficient man-power, disorganised transport and inadequate equipment, are only temporary factors which can be got over; but the basic ones are more serious, and include deforestation, inadequate forest management, failure to develop mature forests, incomplete utilization and insufficient technical personnel.

On the subject of deforestation, it is well known that in large portions of the world continuous mismanagement, fire and unrestricted grazing have led to complete destruction of the original forest cover. Vast denuded areas, deprived of the productive forest, have become wind-swept deserts, barren mountain slopes, and eroded valleys, where agriculture is almost impossible, and living standards have remained at starvation levels for hundreds of millions.

In connexion with insufficient technical personnel, a suggestion might be made that the Food and Agriculture Organisation should create a corps of trained technical officers and foresters. In Great Britain, at least, during the past two years, considerable numbers of young men from the Forces-far too many to be accepted in the existing space in the universities-have been applying to follow forestry courses given at the universities, and at the forestry technical schools training staff of subordinate ranks. 
If the Food and Agriculture Organisation took advantage of this opportunity, it might be possible to have at its disposal a trained international body able to help member governments whose forestry is very far behind the position which it should occupy. It is difficult to see how the Organisation will other. wise obtain a technical trained staff to send out to member governments; most of those with forest departments are themselves very short of staff and have considerable recruiting to do.

It has already been stated that 2,000 million hectares of forest are still left untouched, and constitute perhaps the last remaining opportunity for advancing the frontiers of modern civilization (Boyd Orr's words). These are the world's wood reservoirs; the last great bodies of renewable resources, and they must not be allowed to suffer the fate that has ravaged the forests of many older countries. To help keep them permanently productive must be one of the tasks of the Organisation. There are other tasks. "The afforestation of treeless expanses in China, south eastern Asia, the Inner and Middle East, presents a challenge so vast that only an international effort can hope to answer it. Yet here, forest restoration is the first step to stable agriculture, and to a decent nutrition level for over a thousand million people. In these regions, expanding economy and freedom from want can be little more than phrases until afforestation brings wood for fuel and forests to protect the land against erosive forces, against wind and rain, and against the hot sun. To state the world's forest problem in broad terms is not difficult. There is a shortage of wood, despite the fact that the world has more than enough forest soil to provide wood for the earth's peoples, even under an expanding economy."

On the subject of wood and its importance, and the yearly multiplication of new wood products, Boyd Orr is interesting. "In the Laboratory," he says, "under electronic microscopes, and in test tubes, wood that yesterday was looked upon only as lumber or fuel is being taken apart and its character profoundly altered. The chemical possibilities have barely been touched, and fibre chemistry is opening up an entirely new field of plastics and textiles, and permits the economic pulping of almost any wood species, and of waste from the saw mills. Large factories are being built to convert sawdust and wood unsuitable for lumber and pulp into ethyl alcohol, cattle food and chemicals. Scientists believe that they may soon duplicate in minutes what Nature took millions of years to do, and by converting wood into hydrocarbons, enable the renewable forests to augment the non-renewable reserves of oil." "Our immediate task," says Boyd Orr, "is to increase the available supply of food: our long-range task is to create a world better fed and better sheltered through a wiser use of land, and for both these tasks we must call upon an indispensable ally of agriculture-the forest."

At the present day, afforestation presents another major opportunity for creating forest values over vast areas. The denuded landscapes of south-east Asia and the Middle East, the thousands of millions of miles of desert, the continuous advance of which has never been arrested, can be transformed by tree planting, or by strict closure of large areas of scrub or savanna forest, into fertile lands, capable of supporting large populations. These should be direct profitable objectives, capable of achieving success. But the value of the forest to human welfare has other objectives, for all forests are not measurable in terms of cubic feet of timber, or producers of other marketable commodities. There are great forest influences not capable of being translated into statistical terms, but which have vast importance to the life of the earth's peoples. Even if not productive as a source of wood, forests have still an indispensable function as stabilizers of water flow, protectors of soil and agricultural crops and, especially in the tropics, as sources of food. In many regions afforestation or the maintenance of existing forests is not so much prompted by a need for local wood supplies as it is to stabilize agriculture, shelter livestock, and prevent damaging floods. Ir the case of wheat or corn, world production is largely a function of area planted. In the case of forests it is not so simple. Millions of acres of forest, because of their protective influences, may have little value as producers of wood, and cannot be included as contributing to the wood supplies of the world: but their loss would endanger, and in many cases destroy, agricultural values; and in some sections make human habitation impossible, as has so often been the case in past times.

A nation, therefore, in assessing its requirements in terms of forest area, must appraise its needs both in terms of forest products and of the protective influences of the forest. This need of protective forest varies with topography and geographical location, and the area required may or may not provide a sufficient quantity of forest products for national needs ; but it should be regarded as the minimum to be maintained as forest in order to avoid the economic losses that attend prolonged droughts, floods and lowering of the water table. The report under notice puts the matter in a nutshell: "The world's true balance sheet, then, must take into account more than cubic metres of wood and hectares of forest per caput. The human need for forests cannot be limited to a need for raw materials. Forest policy must be directed to a dual goal-first, sufficient areas of forest to ensure the benefit of their protective influences, and second, whatever forest area may be necessary as a continuing source of raw materials for satisfactory living standards." It should be the task of the Food and Agriculture Organisation to assist governments in attaining this dual goal.

It is not possible to follow the very full statements with reference to what is termed the 'lumber situation' and the lumber shortage in different parts of the world, and the urgent requirements of timber for reconstruction purposes-house rebuilding and build. ing purposes we may say-in most parts of the world, but the Forestry Section of the Organisation has already arrived at a very close appreciation of the seriousness of the present-day position.

The report says : "As far as pulpwood is concerned, no scarcity exists. There are sufficient amounts in the world to meet all present requirements." In Great Britain many would like to know where these amounts exist, as the rationing of paper has been one of the troubles which has probably affected the population, and especially publishers and newspapers, almost as much as the rationing of food.

Perhaps the two most interesting points, apart from the important survey of the world's forest resources and the enormous waste areas carrying neither forest nor agriculture of any value, are that more than 75 per cent of the forests now in use are cut without expert supervision, with no regard for their permanent productivity, and receive no protection against fire, and that large areas of virgin forest 
still remain untapped. In this connexion the Latin American forests receive very considerable notice in the report, and information never before available is disclosed.

The report puts forward some general recommendations which, summarized, deal with : legislation; the introduction of advanced sylvicultural methods; increased yields ; orderly development and management of virgin forests; systematic afforestation of all denuded soils suitable for forest growth; introduction of better utilization, conversion and manufacturing methods; and the stimulation of research in the various branches of forestry, including the development of educational facilities, and the necessity of providing adequate supplies of professional foresters.

In the last paragraph it is stated: "Planned management of the world's forests and planned use of the world's forest soils is the only way to forestall the danger of temporary wood shortages and sur. pluses. Properly applied, F.A.O.'s world programme will ensure that the world's forests and forest products make their full and permanent contribution toward the emergence of a world free from want."

\section{E. P. Stebbing}

\section{CALCULATING MACHINES}

A

DISCUSSION on calculating machines was held at the meeting of the Royal Society on March 4. In opening the discussion, Prof. M. H. A. Newman (University of Manchester) said that it would be confined to machines which are automatic, that is, require no human intervention at any stage; digital, that is, such that separate digits of each number are stored in the machine at every stage (in contrast to 'analogy' machines such as the differential analyser where the numbers are represented by directly measured physical quantities); and 'general-purpose', that is, able without modification to carry out any of a wide variety of computing jobs.

Prof. D. R. Hartree (University of Cambridge) was prevented by illness from attending, and his paper was read by Mr. P. Noble. The general ideas for a large automatic calculating machine are to be found in the designs of Charles Babbage for an 'analytical engine', published more than a century ago. It was to work by means of plungers passing through punched cards, and was to contain a 'store' for numbers, a 'mill' for carrying out arithmetical operations, and a control unit for determining the sequence of operations. The machine would at that time have had to be purely mechanical.

The main components of any digital computing machine were then described. It must have arithmetical units, such as adders and multipliers, which in electrical machines may operate in times of the order of a millisecond. There must be a store to hold numbers and instructions ; an input for accepting data, and an output for furmishing final results ; a means of transferring numbers between different parts of the machine; and a control mechanism which will cause the arithmetical operations to be carried out in the appropriate order. Finally, there must be means of deciding, at any stage, which of two or more alternative procedures shall be adopted, according to some given criterion. It is interesting to note that Babbage clearly recognized the importance of providing this facility.
The first large automatic digital machine built was developed by Prof. $H$ H Aiken and the I.B.M Company, and is now at Harvard. Prof Hartree gave a brief description of its action, which is partly mechanical and partly electrical. The sequence of computing operations is specified by a punched tape, and is controlled by electric relays. In another group of machines, which have been developed largely by the Bell Telephone Laboratory, the storage is on relays, and the arithmetic is done through connexions between groups of relays. The first machine to operate with electronic circuits was the ENIAC, developed at the Moore School of Engineers at Philadelphia [see Nature, 157, 527 (1946)]. It is in some ways an electric analogue of the Harvard machine. An important unit in the machine is the 'master programmer', which controls the sequence not of individual arithmetical operations but of large operations treated as units. This enables the machine to be provided with the discriminating faculty mentioned above.

Prof. Newman said that the idea of a 'universal' machine was introduced in moderm times independ ently of Babbage's work by A. M. Turing, in connexion with certain logical problems. Automatic computing machines have been in use for some years for doing such special jobs as solving algebraic equations, factorizing large integers, making tables of a specified function, etc. A 'universal' machine is one which, when given suitable instructions, will do any of the jobs that can be done by these specialpurpose machines. The machines now being made in Great Britain and the United States will be universal in this sense. In all these machines there is provision for storing numbers, say in the scale of 2 , in certain places or 'houses'; and when the 'attention' of the machine is directed to certain of these rows of 0 's and 1 's, they are read as instructions.

For the machine to have practical utility, the number of orders set up by hand must be very much less than the number of operations to be done, or there will be no saving of time over the use of small desk-machines. This is possible owing to the recurrence in mathematical computations of the same series of operations done over and over again on different data (inductive processes). To take advantage of this, the machine has the power, when so instructed, to shift control to an arbitrary order. This is used to perform repeatedly orders number $a$, $a+1, \ldots a+b$, the data in the relevant 'houses' having meanwhile changed. In order to stop the process at a suitable point, conditional change of control is needed, to take place if the content of a certain 'house' is positive, but not otherwise. Since exact multiplication of two $n$-figure numbers gives a $2 n$-figure number, a stage will eventually be reached when part of the answer has to be thrown away. This leads to the accumulation of 'rounding.off' errors which, when the number of operations is large, may consume the whole answer unless precautions are taken. The difficult problems that arise in this connexion in the inversion of large matrices have been investigated by $J$. von Neumann and $H$. $H$. Goldstine $^{1}$ and also by A. M. Turing ${ }^{2}$. Reference was also made to the importance of providing methods of checking and quickly locating the causes of errors.

Dr. M. V. Wilkes (director of the Mathematical Laboratory, Cambridge) gave a description of the machine EDSAC now under construction at Cam. bridge. The project was started in 1946, after Dr. Wilkes had returned from attending a course at the 